\title{
Wheat Production Simulation Based on the ALMANAC Model of North China Region
}

\author{
Liming Rong ${ }^{1}$, Chengliang Zhang ${ }^{1}$, Xuexia Zhang ${ }^{2}$, Shineng $\mathrm{Wu}^{2} \&$ Zijun Wang ${ }^{2}$ \\ ${ }^{1}$ Environmental Protection Institute of Light Industry, Beijing, China \\ ${ }^{2}$ Key Laboratory of Soil \& Water Conservation and Desertification Combating, Ministry of Education, Beijing \\ Forestry University, Beijing, China \\ Correspondence: Xuexia Zhang, Beijing Forestry University, No. 35, Tsinghua East Road, Beijing, China. Tel: \\ 86-10-6233-6172. E-mail: zhangxuexia@bjfu.edu.cn
}

Received: February 25, 2013 Accepted: June 13, 2013 Online Published: July 20, 2013

doi:10.5539/sar.v2n3p148 URL: http://dx.doi.org/10.5539/sar.v2n3p148

\begin{abstract}
Wheat (Triticumaestivum) is one of the world's three major food crops, whose production is related to regional food security issues. Studies have shown that technological progress and climate change have a significant impact on wheat yield. We selected North China region as the study site because it is the main producer of wheat and because it experiences active climate change. Using the Agricultural Land Management Alternatives with Numerical Assessment Criteriamodel and statistical analysis method, the following factors were considered to determine the dominant factor that affects wheat production: temperature, precipitation, sunshine, and other climatic factors, mechanical power, irrigation area, chemical fertilizer amount, reservoir total storage capacity, and other technical factors.Results showed that wheat productionis affected by both climatic and non-climatic factors in North China region. Increased temperature has a positive impact on wheat production, whereas reduceds unshine has a negative effect. Warm and dry climate trends areconducive to wheat production. Mechanical tillage and fertilization, irrigation, and water conditions are conducive to the production of wheat, among which water condition has the most significant effect onwheat yield improvement. Compared withthe effects of climaticfactors, those of technical factors are more obvious and direct. In the premise of guaranteed technical conditions, the impactof climate changeonwheat production is more evidentindeveloped areas. Underdeveloped areas of wheat production are more dependent on technological progress; in particular, they rely on the use of chemical fertilizers.
\end{abstract}

Keywords: ALMANAC Model, climaticfactor, technological factor, wheat, North China region

\section{Introduction}

Climate changes affect many aspects of the natural world, including the development of human society as a whole. Ecosystem responses to global climate change, especially responses of agro-ecosystem, have increasingly become the focus of geographical scholars and meteorologists. The Fourth Assessment Reportof the Intergovermental Panel on Climate Change in 2007 revealed that global warming amplitude $\left(0.13^{\circ} \mathrm{C} / 10 \mathrm{a}\right)$ nearly doubledin the past 100 years and that the warming amplitude in the northern hemisphere is higher than that in the southern hemisphere. In the past 50 years, the warming amplitude of the North China Plain is $0.25^{\circ} \mathrm{C} / 10 \mathrm{a}$ (Tan et al., 2010), which is a two fold increase in the global temperature during the same period. Climate change alters the distribution of light, heat, and moisture, thereby affecting crop growth, development, production, and regional distribution, as well ascropping systems. Full understanding of crop phenological variation has important theoretical and practical significance in the aspects of crop yield estimation, farming season prediction, and climate change trend prediction.

As the main farming area, North China region accounts for $38.9 \%$ of the national food production in China (Tan et al., 2010). It is an important area of grain production for food export bases in China. Wheat is important to the region or even to the main crop production, which accounts for $56 \%$ of the national output. Furthermore, the output amount of wheat is involved in many aspects of social stability and regional food security. With the current advances in agricultural science and technology, the impact of climate on agricultural production was compensated or concealed (David \& hristopher, 2007). Therefore, new technological means are needed to be analyzed to understand the affecting mechanism of climate change. 
Over nearly 100 years, North China is a typical region with the widest warming magnitude, the fastest warming speed, and the widest zone of reduced precipitation (Ding \& Dai, 1994). The warming period occurs mainly from January to April. The period at which winter wheat turns into green has an important influence on cropyield. Shortage of heat and water resources is acknowledged to be a limiting factor that constrains agricultural production in North China. Climatic warming shortens the growth period of winter wheat, which decreases the production of winter wheat. However, agricultural science and technological innovation can increase wheat production. This study focused on the relationship between climatic warming and technological innovation.

The famous crop models in the world are the CERES wheat model of the U.S., Agricultural Land Management Alternatives with Numerical Assessment Criteria (ALMANAC) model, and World Food Studies model of the Netherlands. These models are used to simulate crop growth and yield formation. Among these models, the ALMANAC model can simulate the dynamic processesof crop growth and development of 36 crops, including grass and trees. Based on the Environmental Policy Integrate Climate model of crop growth in soil erosion, Kiniry and Williams (1996) of the U.S. Department of Agriculture increased the detailed crop growth component and developed the ALMANAC model (Kiniry, 1996). The ALMANAC model has good simulation results in different climatic zones of the U.S. Even in Western China and Northern China, scholars have proven that the ALMANAC model is more applicable (Gao \& ie, 2003; Liu Gang et al., 2008). Based on experimental data, Gao and Xie (2003) showed that the model error of winter wheat in North China by the ALMANAC model is only $5.41 \%$. In the present study, we used the ALMANAC model to estimate the yield of winter wheat in North China in the past 30 years. We also analyzed the changes in wheat production and studied the relationship between the improvements of agricultural technologyand climate change. The current study also considered regional food security issues.

\section{Materials and Methods}

\subsection{Source of Data}

The data used in this paper mainly included the meteorological data and agricultural statistics from 1978 to 2011 . Meteorological data included the observed average temperature, annual precipitation, relative humidity, maximum wind speed, and sunshine hours in meteorological stations of the China Meteorological Administration. Agricultural statistics of the survey were obtained from the National Bureau of Statistics and the Ministry of Agriculture, including the arable land, irrigated area, total power of agricultural machinery, and wheat acreage, production, and production per unit of the provinces in the country.

In addition, the geographic data used in this article were obtained from the geographic data center of China's Administration of Surveying, Mapping, and Geoinformation.

\subsection{Methods}

\subsubsection{ALMANAC Model}

The ALMANAC model parameters were listed as follows: the maximum wheat growth temperature, the temperature limit, the biomass-energy coefficient, and the growing condition index sensitive to the vegetative stage. We input the average temperature ineach month of the corresponding station, the standard deviation of temperature changes, the wind speed and wind direction data, and the sunshine data. Subsequently, we modified the parameters of the model and saved to TXCORN.DAT literature.

Then, we entered the meteorological data of various stations to the ALMANAC model. Finally, we saved and exited. We run the ALMANAC model with the input of TXCORN.DAT to obtain TXCORN.OUT file, where YLD is the area yield in T/HA or tons per hectare yield of the units of measurement.

\subsubsection{Statistical Analysis}

Regression analysis was selected in different wheat planting zones. The wheat yield and its derivative variable were the independent variables. Meanwhile, the dependent variables included climatic factors and non-climaticfactors. Climaticfactors included the temperature, precipitation, and sunshine, whereas non-climatic factors included the total power of agricultural machinery, effective irrigation area, total storage capacity of the reservoir, and amount of chemical fertilizer. Actual statistics and model simulation results were obtaine dusing regression calculationto determine the impact of climatic factors and agricultural scientific and technological progress factors on wheat yield.

\section{Results}

North China has an area of $16,800 \mathrm{~km}^{2}$.It is located south of the Great Wall; north of the Huaihe River, Qinling, and Bailongiiang; and east of the Loess Plateau and Fen River Weihe, including Shanxi, Hebei, Shandong, 
Henan, Beijing, Tianjin, and parts of Jiangsu, Anhui, and other provinces (municipalities). North China has a total of 587 counties and cities, accounting for $1 / 3$ of the country's dry land area. It comprises the largest crop-producing dryland areas in the country. It has atotal sown area of 3743 million ha, in which food crops own area accounts for $81.6 \%$. In addition, winter wheat and corn yields are $56 \%$ and $37.5 \%$ of the country's total crop production, respectively (Yang et al., 2010). Food production in North China is directly related to the food supply of China and to the area of food crops, which are greatly affected by climate change. Therefore, determining the impact of climate change on dry farming in the region is crucial.

In the study area, Henan, Shandong, western and southern Hebei, Shanxi, and southern and northern Anhui have the most concentrated distribution of wheat. The different varieties of wheat distribution change with the latitude, and temperature is the main influencing factor. According to different wheat varieties, three wheat planting zones were distinguished in the study area, namely, the northern zone of spring wheat planting area, the central zone of winter wheat-producing areas in North China, and the southern zone of winter wheat-producing areas in Southern China (Figure 1).

Figure 2 shows the changes in wheat yield per unit area of North China provinces and autonomous regions from 1978 to 2011 . The curve presents a linear upward trend, with an incremental rate of $76.4 \mathrm{~kg} / \mathrm{ha}^{2}$ from the 2215 $\mathrm{kg} / \mathrm{ha}$ in 1978 to the $4841 \mathrm{~kg} / \mathrm{ha}$ in 2011, which is twice the output. The provinces with yields higher than 4000 $\mathrm{kg} / \mathrm{ha}$ are Beijing, Shandong, Henan, and Jiangsu; the provinces with yields between 3000 and $4000 \mathrm{~kg} / \mathrm{ha}$ are Tianjin, Hebei, and Anhui; the provinces with yields lower than $3000 \mathrm{~kg} / \mathrm{ha}$ are Shanxi and Inner Mongolia.

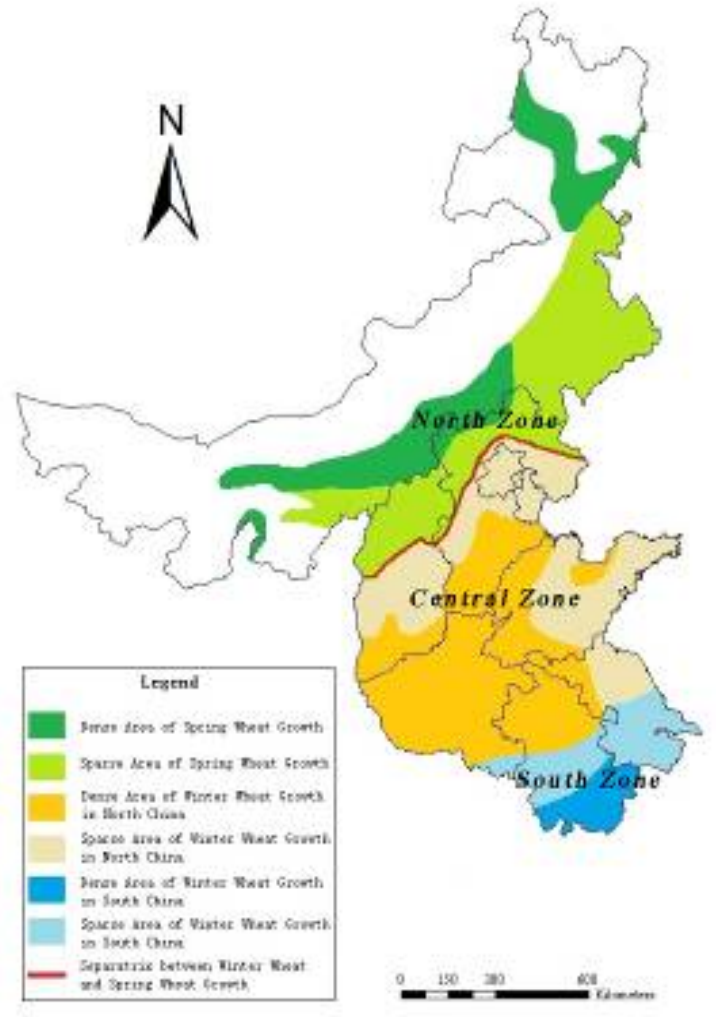

Figure 1. Distribution of wheat in North China region 


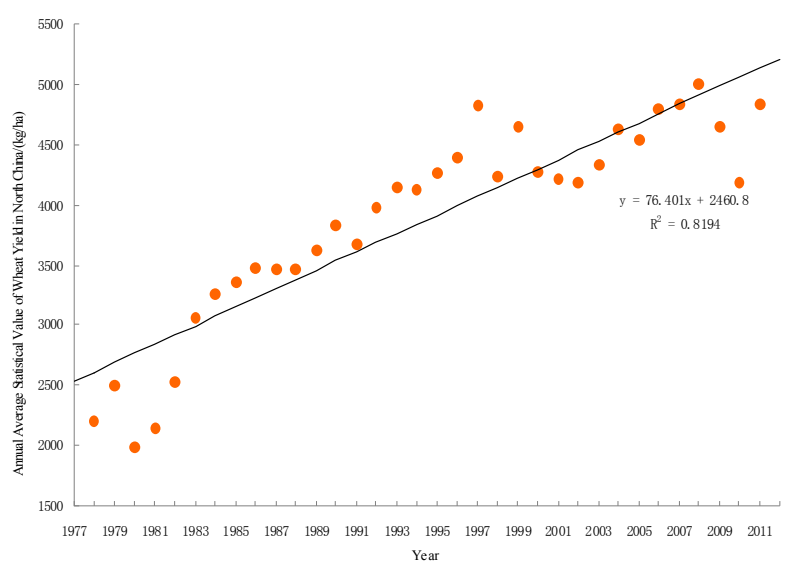

Figure 2. Changes inwheat yields of North China from1978 to 2011

\subsection{Data Processing}

The meteorological and agricultural data were organized into the format required by the ALMANAC model. In addition, according to the regional representativeness of meteorological stations, the simulated yield of wheat was prepared and collected. Furthermore, based on the situation of the provinces, the differences between the simulated yield and the actual production of wheat were analyzed.

When the meteorological data were measured in the province, climatal data were too coarse and did not presentspatial differences. Therefore, the meteorological data were observed by the climatal stations. Each meteorological stationof the study area represented corresponding zones in Figure 3. In the ALMANAC model, simulation stage needs to be provided with more detailed annual number of meteorological data per month. The existing meteorological data format did not meet the requirements of the ALMANAC model. Thus, the format of the data from different meteorological stations should be changed according to need of the model.

Given the different spatial and temporal units of the statistics of the study area, the wheat per unit of production and other non-meteorological factors were measured by units of provinces and year, whereas the meteorological data were observed using the corresponding station and day. However, the ALMANAC model required the temporal units of months. Thus, in statistics, we should combine the stations on behalf of the points with the provinces on behalf of the area, where the divided regions in the province are represented by the various stations in the study area (Figure 3).

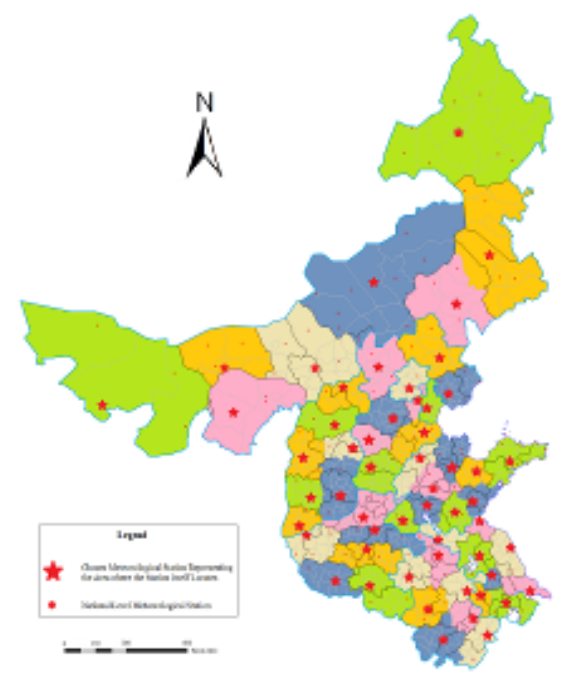

Figure 3. Distribution and zone of stations in North China 
The areas represented by each station were calculated. Subsequently, the areas of the provinces were measured. Then, the proportion of simulated yield was calculated according to the proportion of the weighted average. Finally, the simulated yields of wheat in each planting-wheat zone were calculated.

\subsection{Simulatied Yield and Actual Yield of Wheat}

To simplify the statistical sequence, we assumed that no changesinwheat acreage took place in the countries of North China in the past 30 years. We also assumed that its proportion of the total area was the same as the corresponding proportion of wheat acreage that accounted for the total area of the provinces. We calculated the wheat acreage in zones of meteorological stations, and we used the weighted average.The simulation results in different wheat-planting zones of the ALMANAC model were drawn.

Meteorological data were input into the ALMANAC model according to the format of the year, month, and station. The simulated wheat productions per unitineach station were also drawn. Finally, in accordance with the proportion of the weighted average, we obtained the simulation wheat yield of different wheat-planting zones from 1978 to 2011.

\subsubsection{Northern Zone of Planting Wheat}

Based on the simulation of the northern zone of planting value and the actual statistics, we observed slight changes in the simulated yield of wheat. Compared with the simulated value, the actual statistical value increased and decreased greatly. The actual statistical unit of production was significantly lower than the simulation results from 1978 to 1989 . The actual production was approximately $1000 \mathrm{~kg} / \mathrm{ha}$ higher than the simulated output from 1989 to 2000 (Figure 4a). The output of model and statistical values matched, indicating better fitting from 2000 to 2011 .

As early as 1989 , the wheat per unit of production had reached more stable yields (approximately $5000 \mathrm{~kg} / \mathrm{ha}$ ) in the northern zone. The actual productions per unit were higher than the simulated value from 1989 to 2001 . The actual wheat yields reached the peak from 1992 to 2001, with nearly 6000kg/ha. However, a downward trend was observed beyond 2001 (Figure 4a).

\subsubsection{Central Zone of Planting Wheat}

Theactual production of relatively stable production was approximately $5000 \mathrm{~kg} / \mathrm{ha}$ in the central zoneof planting wheat. This result agrees with the outputs of the ALMANACmodel (Figure 4b). Slight changes in thesimulated wheat yield were observed in the input meteorological data. This result may be attributed to the effect of wheat varieties, fertilization, and other technical factors on wheat production.

\subsubsection{Southern Zone of Planting Wheat}

The southern zone includes Jiangsu with high technical and economic levels and Anhui with undeveloped economics. Only the northern parts of Jiangsu and Anhui provinces belong to North China. However, considering the integrity of administrative region, the southern zone includes the southern Anhui and the central and southern Jiangsu. The cultivation of wheat production in the southern zoneis characterized by the following aspects:

(a) The overall wheat production has been relatively stable since 1978. In a short period of time, a significantly rapid growth was observed, and a relatively stable production was reached (Figure 4c). Compared with a few years before, the wheat production per unit has increased. However, the value is still below $5000 \mathrm{~kg} / \mathrm{ha}$ from 2005 to 2011.

(b) In general, wheat production is relatively stable. Serious yield reduction occurred in individual years, such as in 1981 and 1998 in Jiangsu Province and in 1991 and 1998 in Anhui Province.

(c) Numerous regional differences exist between the simulated value and the actual statistics. According to the ALMANAC model simulation value, the simulated yields of Jiangsu and Anhui provinces are relatively close because of their similar latitudes and hydrothermal conditions. Weather conditions are the major changing variables for the ALMANAC model. Simulated values of wheat yields in Jiangsu and Anhui provinces are similar, i.e., approximately $4200 \mathrm{~kg} / \mathrm{ha}$ to $4300 \mathrm{~kg} / \mathrm{ha}$ and $4000 \mathrm{~kg} / \mathrm{ha}$ to $4100 \mathrm{~kg} / \mathrm{ha}$, respectively. Actual statistical values showed that the wheat yield in Anhui Provinceis approximately $3000 \mathrm{~kg} / \mathrm{ha}$ to $3500 \mathrm{~kg} / \mathrm{ha}$ below the simulated value from 1982 to 2004 . Meanwhile, the wheat yield in Jiangsu Province is approximately $4000 \mathrm{~kg} / \mathrm{ha}$ from 1978 to 2004 . The actual and simulated values in the two provinces have a difference of approximately 200 and $500 \mathrm{~kg} / \mathrm{ha}$, respectively. The gap in Anhui Province is greater than that in Jiangsu Province. 
(a) Northern Zone

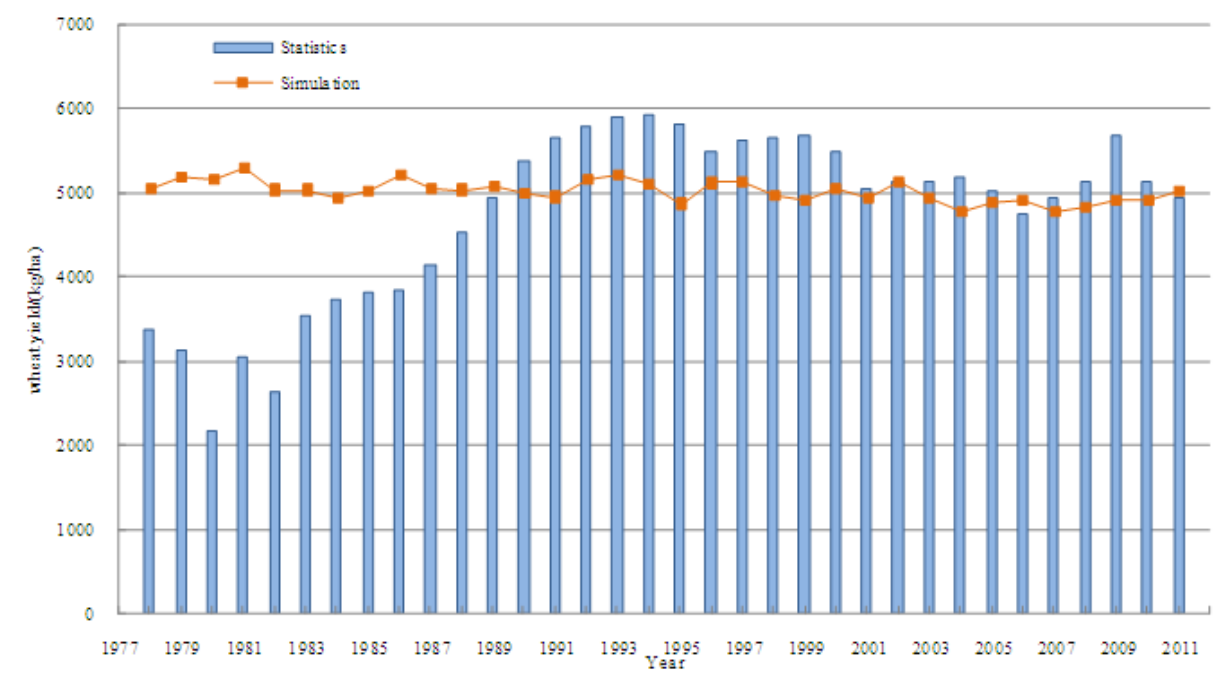

(b) Central Zone

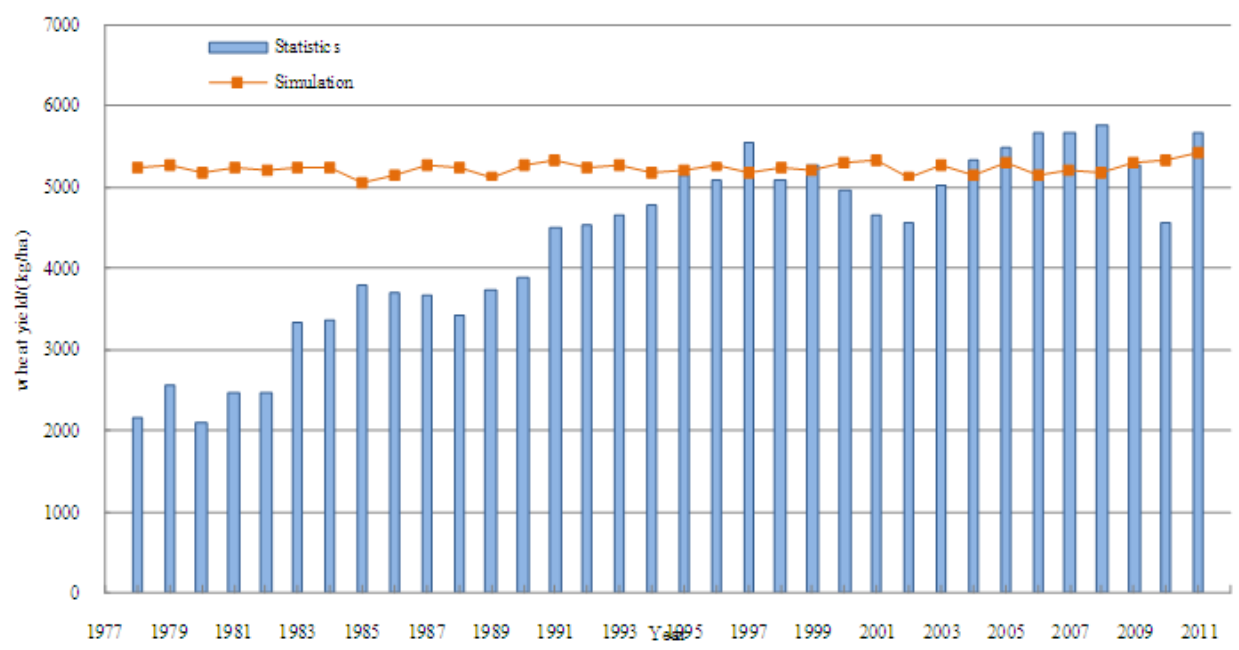

(c) Southern Zone

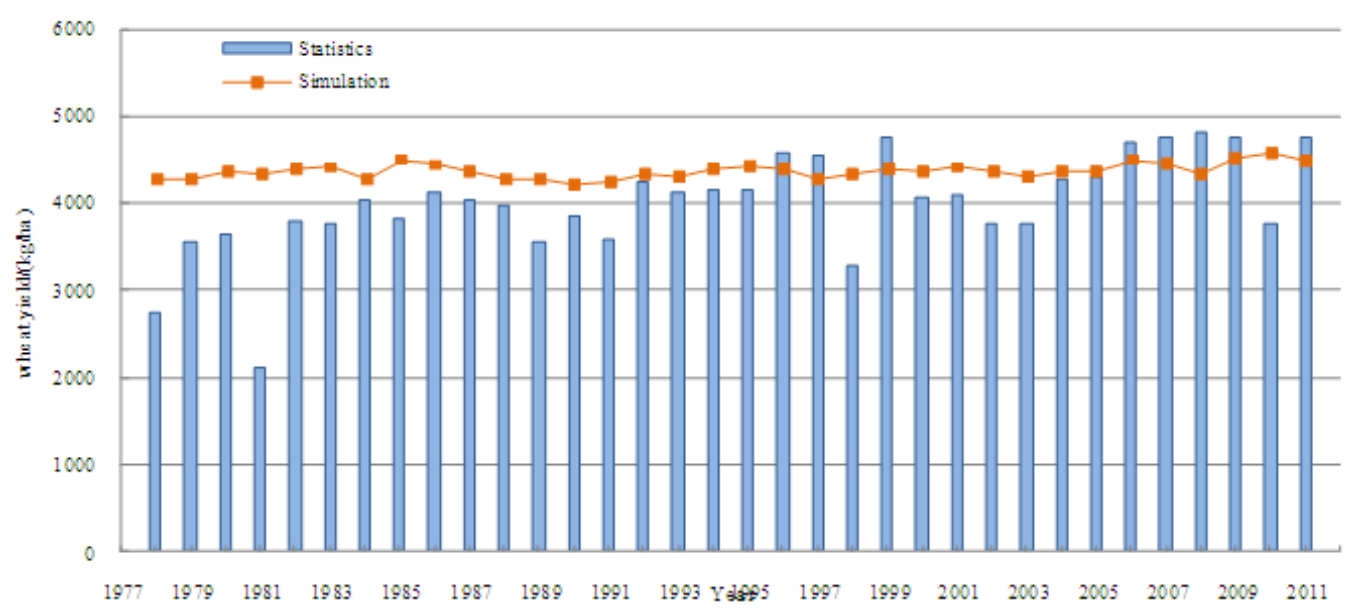

Figure 4. Comparison of simulation and actual wheat yields in North China 


\subsubsection{Comprehensive Comparison and Analysis}

Since 1978, a long-term substantial increase in the wheat yield of North China existed until a more stable value was finally achieved (Figure 2). The actual yield in the northern zone had a similar trend, except in 1990, when higher production levels than the simulated value were achieved, thus, an increase in the trend. The complex internal terrain and planting distribution caused great differences between the simulated value and actual statistical value in the central zone. Based on statistics covering the middle and lower reaches of the Yangtze River plain, major natural disasters in the past years affected wheat yields in the southern zone. The growth rate last seen in 1978 occurred again in 2005. Overall, the wheat yields in the southern zone are less than those in the northern zone despite their similar terrains.

Model simulated values were closer to the last high yields, with small changes (Figure 4). The differences in wheat yield between the simulated value and the actual statistics ranged from $5.60 \%$ to $33.68 \%, 3.59 \%$ to $17.87 \%$, and $0.72 \%$ to $7.10 \%$ from 1978 to 2011,1990 to 2011 , and 2000 to 2011 , respectively. The magnitude of change is much less than the actual statistics from 1978 to 2011 because the relevant parameters of the model used in terrain, soil, and wheat varieties are the results of the 2011 measurements.

\subsection{Factors Influencing Wheat Growth}

In addition to changes in meteorological factors having an impact on the growth of wheat, the role of technological progress cannot be ignored. In this study, we combined meteorological and non-meteorological data to multiple regression analysis to determine both meteorological and non-meteorological factors (Marijn et al., 2012), to derive a relatively sound and comprehensive conclusion, and to evaluate the ALMANAC model simulation results.

\subsubsection{Climatic Factors}

Based on the wheat planting partition, this paper selected the northern, central, and southern zonesto combine with meteorological factor analysis of the impact of climate change.

The regression analyses of different wheat-growing areas were performed. The simulated and actual wheat productions removed the trend. Subsequently, the changes inyield residuals were affected by climate change and technical progress factors. Thus, this paper selected yield residuals for $y$, the total power of agricultural machinery for $x_{1}$, the effective irrigation area for $x_{2}$, the amount of chemical fertilizer for $x_{3}$, thetotal storage capacity of the reservoir for $x_{4}$, the temperature for $x_{5}$, the precipitation for $x_{6}$, and the sunshine for $x_{7}$. The wheat acreages of the first four provinces were combinedon behalf of the non-climaticfactors and the coefficient of variation in the magnitude of change. Two-digit values were used to adjust the respective unit and avoid the different levels of the various variable quantities. The analytical results are as follows:

\section{(a) Analysis on Actual Yields}

Climate change in the past 30 years was analyzed by regression calculation (Table 1). Results showed that the most significant factor in wheat production is air temperature, followed by sunshine. Precipitation showed less impact on wheat growth, and the impacts onvarious regions hadtheir own positive and negative distinctions. Considering the precipitation in the next 30 years, the reasons can explain part of the non-significant correlation, although the inter-annual fluctuations are small. Sunshine exhibited a decreasing trend, and a negative relationship was found between sunshine change and wheat production. These findings indicate that light reduction of resources is not conducive to the growth of wheat.

Table 1. Fitting table of climatic factors' effect on wheat yield

\begin{tabular}{llll}
\hline Types & Zone & Regression Formula & $\mathrm{R}$ \\
\hline & Northern & $\hat{y}=3.52503+0.886756 x_{5}+0.011634 x_{6}-0.1433 x_{7}$ & 0.757 \\
& & & \\
Actual statistical yield & Central & $\hat{\mathrm{y}}=2.182943+0.678692 x_{5}-0.01507 x_{6}-0.33635 x_{7}$ & 0.809 \\
& & $\hat{y}=-1.72855+0.622753 x_{5}-0.00619 x_{6}-0.22482 x_{7}$ & 0.698
\end{tabular}




$\begin{array}{lllll} & \text { Northern } & \hat{y}=4.592103-0.03406 x_{5}+0.001265 x_{6}+0.030721 x_{7} & 0.628 \\ \text { Modeling simulated yield } & \text { Central } & \hat{y}=5.15461+0.063307 x_{5}-0.00041 x_{6}-0.03483 x_{7} & 0.655 \\ & & & \\ & \text { Southern } & \hat{y}=3.884808+0.011011 x_{5}-0.000042 x_{6}-0.001729 x_{7} & 0.139\end{array}$

From regional difference, in Henan province of the central zone, wheat production changes and climate changes fit better, more obvious than the northern and southern zones.

(b) Analysis on Simulated Yields

Compared withthe statistics, the fluctuations of the simulated yields were very small, and light differences were found among the simulated values every year. Lower regression fitting degrees were observed but with higher spatial difference. The regression fits weremore than 0.6 in Beijing City, Henan Province, whereasthe goodness of fit wasvery low in Anhui Province. Among theclimatic factors, air temperature showed the most significant effect, followed by sunshine. The effect of precipitation was negligible, i.e., approximately one-thousandth or even smaller.

The ALMANAC model was used to conclude that climate affectstheextreme climate input model. The results in soil properties, topography, and natural impact factor were assumed to be constant. For example, fertilization and irrigation conditions were assumed to have no effects, and the impact of climate change on wheat production was relatively limited.

\subsubsection{Analysis on Non-Climatic Factors}

The impact of technological advances in the study on wheat production required consideration of machinery, irrigation, fertilization, and irrigation factors. The regression analysis was used, and the results are shown in Table 2.

As shown in Table 2, the non-climatic factors' effect on wheat yield was greater than that of climatic factors for a good degree of fitting in the study area. The highest quality of fit about technical factors' regression was observed in the central zone. Therefore, technological progress has greater effectonwheat growth than climatic factors in the central zone.

Table 2. Fitting table of non-climatic factors' effect on wheat yield

\begin{tabular}{|c|c|c|}
\hline Zone & Regression Formula & $\mathrm{R}$ \\
\hline Northern & $\hat{y}=4.291288-0.00643 x_{1}-0.02706 x_{2}+0.302143 x_{3}-0.33861 x_{4}$ & 0.824 \\
\hline Central & $\hat{\mathrm{y}}=5.571008+0.191558 x_{1}-0.39735 x_{2}+0.014671 x_{3}+0.610519 x_{4}$ & 0.974 \\
\hline Southern & $\hat{y}=7.132907+0.125021 x_{1}-0.41608 x_{2}+0.047954 x_{3}+0.590196 x_{4}$ & 0.833 \\
\hline
\end{tabular}

Fertilization greatly promotes wheat yield. Its contribution value is much higher than in other regions, especially in the cultivation in the northern zone. The wheat production relies heavily on the use of chemical fertilizer in the northern zone.

Different irrigation and water conservancy areas under cultivation, irrigation, and waterwere found to have a negative impact on wheat production in the northern zone. Specific analysis revealed that irrigation and water conservancy reached a higher value and remained stable in the northern zone. In the northern zone of wheat per hectare, calculations by the average area showed thatwater conservancy and irrigation resources were much higher in the northern zone than in the central and southern zones. In obvious growth of irrigation and water 
conservancy, further development of chemical fertilizer will facilitate the development of wheat production. Therefore, irrigation and waterare significantly negatively correlated with wheat production.

Although water conservancy had a positive effect on wheat production, the correlation coefficient (R) of irrigation on wheat production was negative in the central and southern zones because of inadequate irrigation. The correlation coefficient of water conservancy on wheat yield was approximately 0.6 , and the positive influence of water conservancy was higher than the negative influence of the irrigation. Improvement of water conditions largely promoted wheat production in the central and southern zones. Unlike the northern zone, which has good water conservancy and saturated water conditions, further improvement is required in the southern zone.

The impact of water conservancy on wheat growth was found to besimilar to that of mechanical tillage. For saturated machinery power, a negative correlation was found between wheat yield and fertilizer in the northern zone. Meanwhile, mechanical growth showeda positive impact on the growth of wheat production. Therefore, increased machinery power promotes wheat production in these areas.

\subsubsection{Comprehensive Analysis on Climatic and Non-Climatic Factors}

Results of comprehensive analysis of meteorological data and technical data of each of the wheat-growing areas are shown in Table 3.

The impact of climatic factors is less obvious, although temperature has higher contribution to wheat growth as compared with other technical factors. Wheat productions increased with rising temperature in the past 30 years. However, a low correlation coefficient of only 0.013 was calculated in the southern zone with significantly higher temperatures and lower promoting wheat productions. This value is significantly lower than the 0.609 and 0.377 of the northern and central zones, respectively.

The effects of chemical fertilizer and climatic factors on wheat production were more obvious in the central and southernzones than in the northern zone. The chemical fertilizer impact factor of the northern zone $(0.219)$ was greater than that of the central $(0.017)$ and southern $(0.052)$ zones.

Wheat production is affected by rising temperatures in the northern zone. The correlation coefficient of 0.609 in the northern zone was higher than the 0.377 of the central zone and 0.013 of the southern zone. The impact of reduced sunshine was more obvious in the northern zone $(0.130)$ than in the central $(-0.067)$ and southern $(-0.020)$ zones. In the past 30 years, precipitation had a positive coefficient in the northern zone with decreasing precipitation, whereas no obvious changes were observed in the central and southern zones. Therefore, a certain degree of reduced precipitation promotes wheat growth.

Table 3. Fitting table of climatic and non-climatic factors' effect on wheat yield

\begin{tabular}{|c|c|c|}
\hline Zone & Regression Formula & $\mathrm{R}$ \\
\hline Northern & $\begin{aligned} \hat{y}= & -0.32834-0.00046 x_{1}-0.00216 x_{2}+0.218883 x_{3} \\
& -0.31335 x_{4}+0.608728 x_{5}+0.003144 x_{6}-0.12958 x_{7}\end{aligned}$ & 0.871 \\
\hline Central & $\begin{aligned} \hat{y}= & 3.86849+0.173518 x_{1}-0.33866 x_{2}+0.016848 x_{3} \\
& +0.212628 x_{4}+0.377373 x_{5}-0.00371 x_{6}-0.06707 x_{7}\end{aligned}$ & 0.981 \\
\hline Southern & $\begin{aligned} \hat{y} & =8.76084+0.138981 x_{1}-0.46781 x_{2}+0.052425 x_{3} \\
& +0.529936 x_{4}+0.013299 x_{5}-0.0085 x_{6}-0.02031 x_{7}\end{aligned}$ & 0.871 \\
\hline
\end{tabular}

In view of the goodness of fit, a comprehensive analysis of the fit wasnot only higher than the impact of climatic factors but also higher than that of technical factors. These data suggest that the combination of technical and climatic factors hasamore significant impact on wheat production than either of the two alone. 


\section{Conclusions and Discussions}

In previous studies of crop growth, specifically wheat growth, the effects of climaticfactorsare often considered, whereas those of technical factors are ignored (Juan et al., 2008; Jing et al., 2011). These studies are in line with the principle of scientific theory controlling variables, although the relationship between climate factors and technical factors can be easily overlooked. We used meteorological data, technical data, and statistics of wheat per unit of production for nearly 30 years in North China. We combined these data with the simulation of the ALMANAC model of wheat production and conducted a comprehensive analysis on the impact of climatic and non-climatic factors on wheat yield. The following conclusions were obtained.

(a) The smallest error $(0.72 \%)$ of wheat production simulation by the ALMANAC model is more applicable in North China. Simulation accuracy is higher in economically developed plain regions but lower in underdeveloped mountainous regions. The maximum simulation error obtained is $33.68 \%$. This result can be attributed to regional characteristics, such as soil, fertilization, irrigation, terrain, and wheat varieties. In addition, the simulated valueswerecompared with statistical values, which can be poor pre-fitting and good late-fitting. Given that soil, fertilization, irrigation, and other conditions should be considered in the simulation, the simulated value is generally higher and close to the actual output value with new improved technology and good service in recent years.

(b) In North China, wheat productionisaffected by climatic and non-climatic factors. Increased temperature has a positive impact on wheat production, whereas reduced sunshine has a negative impact. Small changes in precipitation have relatively small impact on wheat yield. Accordingly, warm and dry climate trends with rising temperature and reduced precipitation favor wheat production.

(c) The effects of technical factors are more obvious and direct than those of climatic factors. Technical factors, such as the progress of mechanical tillage, fertilization, irrigation, and water conditions, are conducive to the production of wheat, which is particularly evident in the construction of water conservancy conditions. The effects of technology and climate on wheat output vary with the different levels of economic and technological development of different areas. Under the premise of the guaranteed technical conditions, wheat production is not only obviously affected by climate change but also by the use of chemical fertilizers in economically developed regions. In underdeveloped areas, wheat production is more dependent on technological progress. Since 1978, the wheat production of North China has been long and sustained, and has gained substantial growth, until a relatively stable value was reached. The increasing trend has been maintained in the recent years.

(d) The climatic and technical factors have different effects on the wheat output in different regions in different years. In most areas, the effects and roles of climate change are smaller than those of technological progress. Since 1978, the wheat-yield increase in the provinces and counties in North China are more substantial and continuous. During this period, the impact of technological progress and investment in services is very tremendous, with good fitting of increased yields and several technical factors of the non-climaticchange. A large difference between simulated and statistical values of climatic factors can be observed, indicating that wheat output growth is due to technical factors at this stage.

(e) The level of economic and technological development is influenced by technology and climate change. The extent of impacts is also different. In areas with high level of technical and economic resources, such as Beijing, the goodness of fit in a regression analysis of climate change impact is higher, and a relatively stable value with high accuracy of model simulation is reached earlier. Meanwhile, in areas with lower level of technical and economic resources, such as Henan Province, the statistical production has maintained growth momentum, whereas a more stable simulated value is affected by non-climatic factors. A high correlation between the production progress and technological progress exists in Henan Province. This result can be attributed to the fact that developed areas can provide support in technical factors. However, climate change has become an uncontrollable factor resulting in yield changes. Simultaneously, long-term progress of technical and economic input masked the impactof climate change on wheat outputs in underdeveloped areas to a certain extent. In addition to climatic factors, wheat output is also affected by technical factors in underdeveloped areas.

Further research is needed to elucidate the climatic elements and non-climatic factors affecting wheat growth and to identify other applications of the ALMANAC model.

(a) In data collection and processing, such as further analysis at the region or county level, regional differences in error can be avoided to improve the accuracy.

(b) Further study on the roles and effects of climaticand technical factors on wheat growth is required to reveal the physiological mechanism between these factors, rather than a simple correlation analysis. 
(c) TheALMANAC model also requires a more in-depth research to gather meteorological and non-meteorological data, such as soil, fertilization, irrigation, and terrain. Further studies should also be conducted to verify whether the ALMANAC model can be used to study watershed crop growth in China and whether it can be applied to a larger range of statistics, representative region of climatic stations, and more complex geographical situations.

\section{Acknowledgements}

The study was sponsored by the Finance Project of Beijing City, the National Basic Research Program of China (Grant No. 2012CB955403) and Students Research Training Program (Grant No. 120201). The authors are grateful to the journal's editor and anonymous reviewers for their constructive comments on earlier version of the paper.

\section{References}

David, B. L., \& Christopher, B. F. (2007). Global scale climate-crop yield relationships and the impacts of recent warming. Environmental Research Letters, 2, 014002:17. http://dx.doi.org/10.1088/1748-9326/2/1/014002

Ding, Y. H., \& Dai, X. S. (1994). Changes of temperature in recent 100 years in China. Meteorological Monthly, 20(12), 19-26. http://dx.doi.org/10.7519/j.issn.1000-0526.1994.12.008

Fulu, T., \& Zhao, Z. (2010). Adaptation of maize production to climate change in North China Plain: Quantify the relative conatributions of adaptation options. European Journal of Agronomy, 33, 103-116. http://dx.doi.org/10.1016/j.eja.2010.04.002

Gao, X. F., \& Xie, Y. (2003). Simulation of winter wheat growth by using ALMANAC crop growth model. Journal of Natrual Resources, 18(4), 505-510. http://dx.doi.org/10.3321/j.issn:1000-3037.2003.04.016

Guo, R. P., Lin, Z. H., Mo, X. G., \& Yang, C. L. (2010). Responses of crop yield and water use efficiency to climate change in the North China Plain. (Special Issue: Crop water use efficiency at multiple scales.). Agricultural Water Management, 97(8), 1185-1194. http://dx.doi.org/10.1016/j.agwat.2009.07.006

Intergovermental Panel on Climate Change. (2007). IPCC fourth assessment report: Climate change 2007: The physical scientific basis. Cambridge, United Kingdom \& New York, NY, USA: Cambridge University Press.

Jing, W., Enli, W., \& De, L. L. (2011). Modelling the impacts of climate change on wheat yield and field water balance over the Murray-Darling Basin in Australia. Theoretical and Applied Climatology, 104, 285-300. http://dx.doi.org/10.1007/s00704-010-0343-2

Jinxia, W., Robert, M., Ariel, D., Jikun, H., Scott, R., \& Lijuan, Z. (2009). The impact of climate change on $\begin{array}{lllll}\text { China's agriculture. } & \text { Agricultural } & \text { Economics, } & 40, & \text { 323-337. }\end{array}$ http://dx.doi.org/10.1111/j.1574-0862.2009.00379.x

Juan, F. García, Q., Gaby, D., Reinhart, C., Jos, V. O., \& Bart, M. (2008). Scaling from stand to landscape scale of climate change mitigation by afforestation and forest management-a modeling approach. Climatic Change, 86, 397-424. http://dx.doi.org/10.1007/s10584-007-9297-5

Kiniry, J. R., Asnderson, M. A., Williams, J. R., Charles, R. T., \& Mark, A. H. (1996). Simulating Alano Switchgrass with the ALMANAC model. Agronomy Journal, 88, 602-606. http://dx.doi.org/10.2134/agronj1996.00021962008800040018x

Liu, G., Xie, Y., Gao, X. F., \& Feng, Y. J. (2008). Sensitivity analysis on parameters of ALMANAC crop model. $\begin{array}{llll}\text { Chinese Journal } & \text { 259-263. }\end{array}$ http://dx.doi.org/10.3969/j.issn.1000-6362.2008.03.003

Marijn, V. D. V., Francesco, N. T., Anton, V., \& Fayçal, B. (2012). Impacts of extreme weather on wheat and maize in France - evaluating regional crop simulations against observed data. Climatic Change, 113(3-4), 751-765. http://dx.doi.org/10.1007/s10584-011-0368-2

National Bureau of Statistics of China. (2011). China statistical yearbook. Retrieved from http://www.stats.gov.cn/tjsj/ndsj/

Olivier, C., Sepo, H., \& Mark, T. (2011). Sensitivity of southern African maize yields to the definition of sowing dekad in a changing climate. Climatic Change, 106, 267-283. http://dx.doi.org/10.1007/s10584-010-9924-4

People's Republic of China Ministry of Agriculture. (2005). China Agricultural Statistic. Beijing CA: China Agriculture Press. 
Swaminathan, M. S., \& Kesavan, P. C. (2012). Agricultural Research in an Era of Climate Change. Agricultural Research, 1(1), 3-11. http://dx.doi.org/10.1007/s40003-011-0009-z

Tan, F. Y., Wang, J. L., \& Song, Y. B. (2010). Characteristics of Climate Change in the North China Plain for $\begin{array}{llllll}\text { Recent } & 45 & \text { Years. } & \text { Meteorological }\end{array}$ http://dx.doi.org/10.7519/j.issn.1000-0526.2010.5.005

Yang, J. Y., Mei, X. R., Yan, C. R., \& Liu, Q. (2010). Study on spatial pattern of climatic resources in North China. Chinese Journal of Agrometeorology, 31(S1), http://zgnyqx.ieda.org.cn/CN/abstract/abstract901.shtml\#abstract_tab_content

\section{Copyrights}

Copyright for this article is retained by the author(s), with first publication rights granted to the journal.

This is an open-access article distributed under the terms and conditions of the Creative Commons Attribution license (http://creativecommons.org/licenses/by/3.0/). 